Article

\title{
Overexpression of S-Adenosyl-L-Methionine Synthetase 2 from Sugar Beet M14 Increased Arabidopsis Tolerance to Salt and Oxidative Stress
}

\author{
Chunquan Ma ${ }^{1,2}$, Yuguang Wang ${ }^{3}$, Dan Gu ${ }^{1,2}$, Jingdong Nan ${ }^{1}$, Sixue Chen ${ }^{4, *}$ \\ and Haiying $\mathrm{Li}^{1,2, *}$ \\ 1 Key Laboratory of Molecular Biology, College of Heilongiiang Province, College of Life Sciences, \\ Heilongjiang University, Harbin 150080, China; chqm0913@163.com (C.M.); gudan9865@sina.com (D.G.); \\ jingdongnan09@163.com (J.N.) \\ 2 Engineering Research Center of Agricultural Microbiology Technology, Ministry of Education, \\ Heilongjiang University, Harbin 150080, China \\ 3 Key Laboratory of Sugar Beet Genetic Breeding of Heilongjiang Province, Heilongjiang University, \\ Harbin 150080, China; wangyuguang0920@hotmail.com \\ 4 Department of Biology, Genetics Institute, Plant Molecular and Cellular Biology Program, \\ University of Florida, Gainesville, FL 32610, USA \\ * Correspondence: schen@ufl.edu (S.C.); 1999020@hlju.edu.cn (H.L.)
}

Academic Editors: Yikun He, Xuchu Wang and Shaojun Dai

Received: 18 January 2017; Accepted: 10 April 2017; Published: 18 April 2017

\begin{abstract}
The sugar beet monosomic addition line M14 is a unique germplasm that contains genetic materials from Beta vulgaris L. and Beta corolliflora Zoss, and shows tolerance to salt stress. Our study focuses on exploring the molecular mechanism of the salt tolerance of the sugar beet M14. In order to identify differentially expressed genes in M14 under salt stress, a subtractive cDNA library was generated by suppression subtractive hybridization (SSH). A total of 36 unique sequences were identified in the library and their putative functions were analyzed. One of the genes, $S$-adenosylmethionine synthetase $(S A M S)$, is the key enzyme involved in the biosynthesis of $S$-adenosylmethionine (SAM), a precursor of polyamines. To determine the potential role of SAMS in salt tolerance, we isolated BvM14-SAMS2 from the salt-tolerant sugar beet M14. The expression of BvM14-SAMS2 in leaves and roots was greatly induced by salt stress. Overexpression of BvM14-SAMS2 in Arabidopsis resulted in enhanced salt and $\mathrm{H}_{2} \mathrm{O}_{2}$ tolerance. Furthermore, we obtained a knock-down T-DNA insertion mutant of AtSAMS3, which shares the highest homology with BvM14-SAMS2. Interestingly, the mutant atsam3 showed sensitivity to salt and $\mathrm{H}_{2} \mathrm{O}_{2}$ stress. We also found that the antioxidant system and polyamine metabolism play an important role in salt and $\mathrm{H}_{2} \mathrm{O}_{2}$ tolerance in the BvM14-SAMS2-overexpressed plants. To our knowledge, the function of the sugar beet SAMS has not been reported before. Our results have provided new insights into SAMS functions in sugar beet.
\end{abstract}

Keywords: sugar beet M14; S-adenosyl-L-methionine synthetase; salt stress; polyamine; antioxidant system

\section{Introduction}

Soil salinity is a serious ecological problem that affects crop distribution and yield around the world [1-3]. More than $6 \%$ of land throughout the globe is affected by salinization [4]. Thus, improving the salt tolerance of crops to utilize saline soil is of high urgency [5,6]. High concentrations of salt usually lead to ionic imbalance, oxidative damage and nutrient deficiency in plants [2]. In order to adapt to the saline environment, plants can use some strategies allowing for adaptation, which include 
efflux of salt ions, compartmentalization of $\mathrm{Na}^{+}$in vacuoles, synthesis of osmolytes, and increased synthesis of antioxidant enzymes [7]. In these adaptation processes, salt stress regulatory genes are induced, leading to changes in the protein levels that enable adaptation to the salinity conditions. For instance, many genes involved in signal transduction and redox reaction have been identified in several plant species [8]. It is reported that about 2300 ESTs (Expressed equence tags) in some halophytes showed differential expression under salt stress [9-11]. In addition, numerous proteins have exhibited salt stress responses as identified by proteomics studies in several halophytes [12-15].

$S$-adenosyl-L-methionine (SAM) synthetase, one of the salt-responsive genes, is an important enzyme in the synthesis of SAM. Usually, SAM synthesized by SAM synthetase (SAMS) from methionine and ATP, forms a universal methyl group donor involved in numerous transmethylation reactions [16]. It plays a vital role in metabolism and development regulation, as well as abiotic and biotic stresses [17,18]. Additionally, it functions as a precursor for the synthesis of polyamines (PAs), which are involved in regulating plant responses to abiotic or biotic stresses [19]. In the process of PA biosynthesis, SAM can be decarboxylated by SAM decarboxylase (SAMDC) to form decarboxylated SAM (dcSAM). Then, dcSAM provides aminopropyl groups to putrescine (Put) for sequential formation of spermidine (Spd) and spermine (Spm), catalyzed by Spd synthase (SPDS) and Spm synthase (SPMS), respectively. Put, Spd and Spm are major constituents of polyamines in plants. It is reported that up-regulation of polyamine synthesis by SAMDC-overexpressing tobacco plants displayed a significant increase in the contents of soluble conjugated PAs and resulted in enhanced tolerance to salinity [20]. On the basis of the SAM functions, a hypothesis of SAMS involved in plants abiotic or biotic stress tolerance was proposed. For example, transgenic plants overexpressing SISAMS1 exhibited a strong tolerance to alkali stress and maintained a balance of nutrients under stress conditions [21]. Overexpressing MfSAMS1 in transgenic plants led to high accumulation of SAM and promoted polyamine synthesis, which in turn improved $\mathrm{H}_{2} \mathrm{O}_{2}$-induced antioxidant protection and increased tolerance to various abiotic stresses [22]. It is also reported that overexpression of SsSAMS2 from a halophyte plant Suaeda salsa in tobacco led to salt stress tolerance [23].

Sugar beet monosomic addition line M14 was acquired from the hybridization between Beta vulgaris L. and Beta corolliflora Zoss [24]. The M14 line has shown characteristics of apomixis and tolerance to abiotic stress [25-27]. In this study, we employed suppression subtractive hybridization (SSH) to investigate alterations in the transcriptional profiles of the M14 line under salt stress. Furthermore, BvM14-SAMS2 was found to be increased in the transcriptional level under $\mathrm{NaCl}$ treatment. In order to determine the role of salt-induced BvM14-SAMS2 in salt response, BvM14-SAMS2 was cloned using the rapid amplification of complementary deoxyribonucleic acid ends (RACE) method. To investigate the gene functions, transgenic Arabidopsis overexpressing BvM14-SAMS2 was generated and used to examine antioxidant activity and polyamine contents. The results demonstrated that the overexpression of BvM14-SAMS2 can confer salt and $\mathrm{H}_{2} \mathrm{O}_{2}$ stress tolerance in the transgenic plants.

\section{Results}

\subsection{Identification of Differentially Expressed M14 Genes under Salt Stress Using SSH}

To identify the differentially expressed genes in the M14 line under salt stress, SSH was employed to profile differential gene expression following $400 \mathrm{mM} \mathrm{NaCl}$ treatment for 7 days. The cDNAs synthesized from the sugar beet M14 root and leaf mRNAs under control conditions were used as drivers, and those from roots and leaves under salt stress were selected as testers. A total of 500 colonies were randomly selected for sequencing. After counting assembly, 36 unigenes were acquired and annotated by comparison with the non-redundant (Nr) database using Blastx (Table 1). Furthermore, gene classification was carried out by the Gene Ontology (GO) method (Figure 1). For example, many of the genes were classified in terms of catalytic activity (39\%) according to their molecular functions. Interestingly, among the differentially expressed genes, leaf (L) 22 and root (R) 6 EST clones 
showed high homology with plant SAMS, which has been reported to play an important role in stress tolerance $[17,18]$.

Table 1. cDNA clones isolated from a subtractive hybridization library of salt stressed sugar beet M14 roots $(\mathrm{R})$ and leaves $(\mathrm{L})$.

\begin{tabular}{|c|c|c|c|c|}
\hline Unigene Number & Length (bp) & Annotation & Score & $E$-Value \\
\hline L1 & 354 & Glutathione S-transferase & 159 & $6 \times 10^{-33}$ \\
\hline L2 & 231 & Late embryogenesis abundant protein & 73 & $1 \times 10^{-5}$ \\
\hline L3 & 174 & Chloroplastic chlorophyll a-b binding 8 & 154 & $2 \times 10^{-27}$ \\
\hline L4 & 150 & $\begin{array}{l}\text { ATP-binding cassette transporter } \\
\text { C family member } 14\end{array}$ & 70 & $3 \times 10^{-11}$ \\
\hline L5 & 392 & $\mathrm{Ca}^{2+}$ transporting ATPase & 260 & $4 \times 10^{-78}$ \\
\hline L6 & 237 & $\begin{array}{l}\text { MYB (v-myb avian myeloblastosis viral } \\
\text { oncogene homolog) transcription factor }\end{array}$ & 52 & $2 \times 10^{-7}$ \\
\hline L7 & 359 & Salt-induced hydrophilic protein & 70.3 & $2 \times 10^{-9}$ \\
\hline L8 & 467 & Aldehyde dehydrogenase family 7 A1 & 119 & $1 \times 10^{-32}$ \\
\hline L9 & 233 & Cysteine proteinase inhibitor & 134 & $1 \times 10^{-8}$ \\
\hline L10 & 221 & Aldehyde dehydrogenase & 123 & $3 \times 10^{-13}$ \\
\hline L11 & 274 & S-adenosylmethionine decarboxylase & 155 & $1 \times 10^{-36}$ \\
\hline L12 & 148 & Pyruvate kinase family protein & 89 & $4 \times 10^{-18}$ \\
\hline L13 & 274 & Cysteine protease & 63 & $1 \times 10^{-7}$ \\
\hline L14 & 297 & Short-chain dehydrogenase & 73 & $7 \times 10^{-11}$ \\
\hline L15 & 246 & Carboxyl-terminal-processing protease & 132 & $1 \times 10^{-30}$ \\
\hline L16 & 301 & MYB transcription factor & 94 & $2 \times 10^{-7}$ \\
\hline L17 & 144 & $\begin{array}{l}\text { Short-chain dehydrogenases/reductases } \\
\text { family 7C }\end{array}$ & 198 & $5 \times 10^{-8}$ \\
\hline L18 & 326 & Vacuole ATPase subunit A & 144 & $3 \times 10^{-66}$ \\
\hline L19 & 528 & Putative mitochondrial carrier protein & 163 & $5 \times 10^{-77}$ \\
\hline L20 & 416 & Nitrite reductase & 254 & $4 \times 10^{-66}$ \\
\hline L21 & 512 & Lipid transfer protein & 184 & $4 \times 10^{-45}$ \\
\hline L22 & 314 & $S$-adenosylmethionine synthase 2 & 239 & $1 \times 10^{-61}$ \\
\hline L23 & 763 & Phosphoglycerate kinase & 407 & $8 \times 10^{-112}$ \\
\hline L24 & 236 & Cellulose synthase-like protein E6 & 71.2 & $5 \times 10^{-11}$ \\
\hline L25 & 450 & High-mobility group B6 transcription factor & 69 & $3 \times 10^{-2}$ \\
\hline L26 & 544 & Heat- and acid-stable phosphoprotein & 95 & $3 \times 10^{-16}$ \\
\hline L27 & 236 & Thioredoxin domain 2 & 68 & $6 \times 10^{-31}$ \\
\hline L28 & 437 & Hypothetical protein & 109 & $5 \times 10^{-4}$ \\
\hline L29 & 197 & $\begin{array}{l}\text { DNA replication licensing factor } \\
\text { minichromosome maintenance } 4 \text { (MCM4) }\end{array}$ & 88 & $2 \times 10^{-2}$ \\
\hline R1 & 245 & Thioredoxin domain 1 & 96 & $3 \times 10^{-13}$ \\
\hline $\mathrm{R} 2$ & 364 & S-adenosylmethionine synthase 2 & 194 & $1 \times 10^{-22}$ \\
\hline R3 & 208 & $\begin{array}{l}\text { WD (Trp-Asp) repeat } \\
\text { phosphoinositide-interacting }\end{array}$ & 174 & $6 \times 10^{-30}$ \\
\hline R4 & 447 & AAA-type ATPase family protein & 143 & $4 \times 10^{-12}$ \\
\hline R5 & 182 & Putative senescence-associated protein & 121 & $6 \times 10^{-2}$ \\
\hline R6 & 394 & S-adenosylmethionine synthase 2 & 74 & $3 \times 10^{-7}$ \\
\hline R7 & 113 & $60 \mathrm{~S}$ ribosomal protein L19-3 & 863 & $4 \times 10^{-14}$ \\
\hline
\end{tabular}


(a)

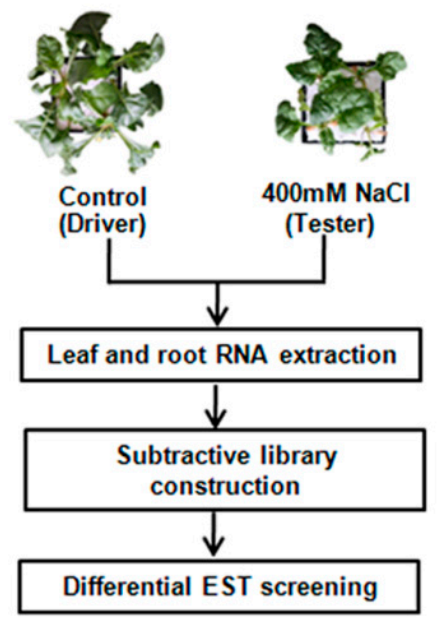

(b)

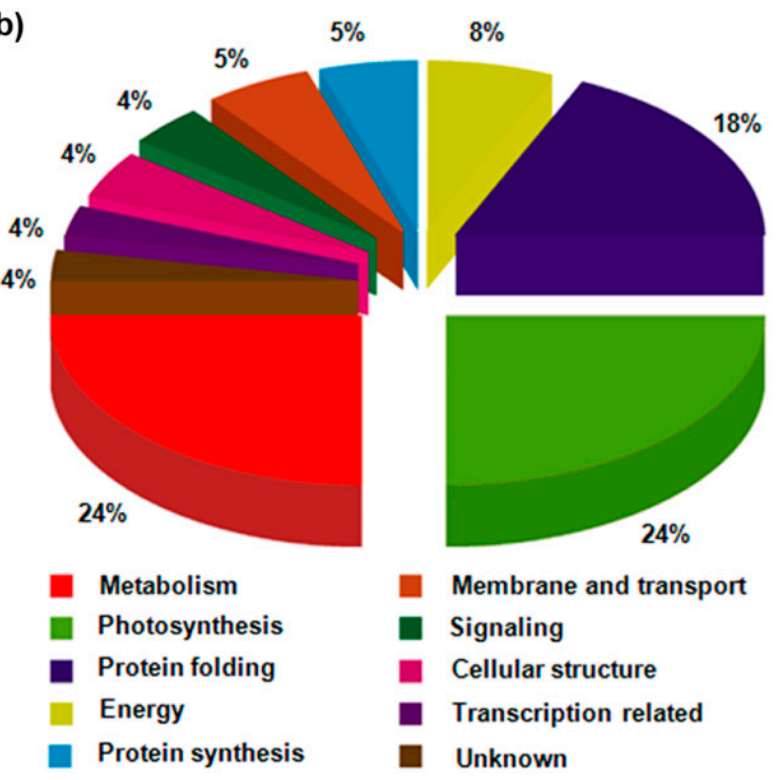

Figure 1. Experimental scheme of screening differentially expressed genes by suppression subtractive hybridization (SSH) and functional classification of the identified genes using the UniProt database. (a) Experimental scheme; (b) Functional classification of the differential genes; EST stands for expressed sequence tag.

\subsection{Cloning of a BvM14-SAMS2 Gene and Sequence Analysis}

Based on the EST sequences (L 22 and R 6) matched to a BvM14-SAMS2 gene, a full-length cDNA clone was obtained using a $5^{\prime}-/ 3^{\prime}-\mathrm{RACE}$ extension method. Sequence analysis confirmed the clone to be the SAMS gene. As shown in Supplementary Materials Figure S1, the full-length BvM14-SAMS2 was comprised of $1538 \mathrm{bp}$, containing an open reading frame of $1182 \mathrm{bp}$ nucleotides, which encodes a 393-amino acid protein with a molecular mass of $42.99 \mathrm{kDa}$ and a pI (isoelectric point) of 5.59. No signal peptide was found.

Phylogenetic analysis of BvM14-SAMS2 was performed using a neighbor-joining method with MEGA4.1. The phylogenetic tree reflects both the taxonomy and specificity. As shown in Figure S2, BvM14-SAMS2 forms a clade with the Arabidopsis thaliana AtSAMS3. The result showed that the $B v M 14-S A M S 2$ was closely related to monocotyledon and other plants, and SAMS genes were relatively conserved in evolution.

\subsection{Analysis of BvM14-SAMS2 Response to Salt Stress}

BvM14-SAMS2 transcript levels in different tissues were detected. Under normal control conditions, high levels of BvM14-SAMS2 transcript were found in roots, but a small quantity of BvM14-SAMS2 transcript was detected in flowers, leaves and stems (Figure 2a). We also determined AtSAMS3 gene expression in different tissues of A. thaliana (Figure S3). AtSAMS3 expression was strong in roots, and its expression patterns were not substantially different from those of BvM14-SAMS2 in sugar beet M14. These results confirmed that BvM14-SAMS2 is closely related to AtSAMS3, and we speculated the function of BvM14-SAMS2 in sugar beet M14 may be similar to AtSAMS3.

The responses of BvM14-SAMS2 mRNA to salt stress were determined in roots and leaves using quantitative reverse transcription-polymerase chain reaction (RT-PCR). The induction of $B v M 14-S A M S 2$ transcript was found much earlier in roots than in leaves (Figure $2 \mathrm{~b}, \mathrm{c}$ ). High levels of BvM14-SAMS2 transcripts were observed at $12 \mathrm{~h}$ and $24 \mathrm{~h}$ after salt treatment in roots and leaves, respectively (Figure 2b,c). These results showed that the expression of BvM14-SAMS2 was significantly up-regulated by salt stress. 
(a)

(b)
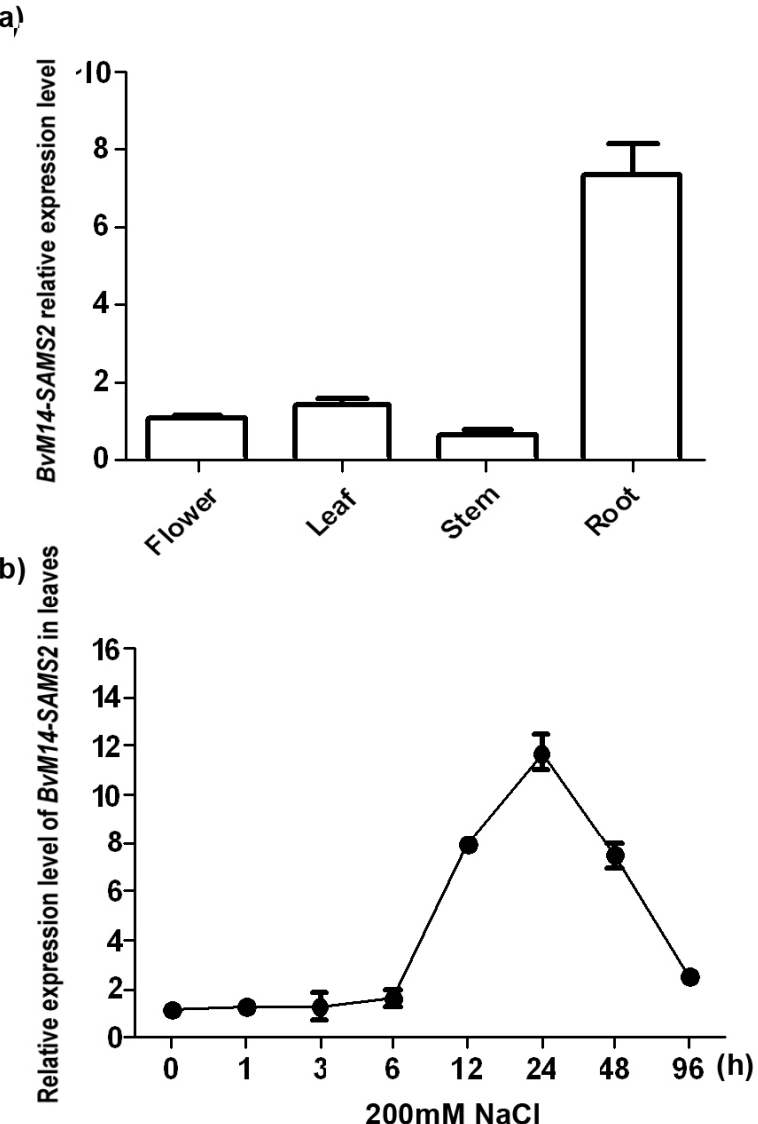

(c)

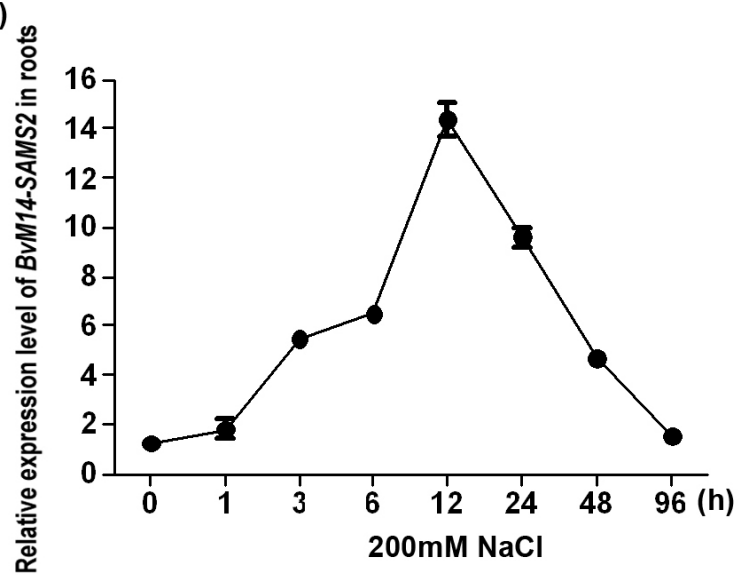

Figure 2. Tissue specific expression of BvM14-SAMS2 gene in the M14 plants and induction of the BvM14-SAMS2 mRNA in response to salt stress. (a) Real time-PCR detection of BvM14-SAMS2 gene in different tissues. Time-course analysis of BvM14-SAMS2 relative expression levels in leaves (b); and roots (c) of the M14 plants under $200 \mathrm{mM} \mathrm{NaCl}$ stress. Data for real time-PCR analysis are the means of three biological replicates and three technology replicates (standard deviation, SD), separately. Each replicate contains five sugar beet seedlings. The $18 \mathrm{~S}$ rRNA gene was used as the internal control for relative expression analysis.

\subsection{Overexpression of BvM14-SAMS2 Confers Enhanced Salt and $\mathrm{H}_{2} \mathrm{O}_{2}$ Tolerance in Arabidopsis}

To determine the functions of BvM14-SAMS2 under salt stress conditions, we created transgenic Arabidopsis plants that over-express the BvM14-SAMS2 gene. Two homozygous $\mathrm{T}_{3}$ overexpressed BvM14-SAMS2 transgenic lines (OX1 and OX2) were identified by RT-PCR analysis (Figure 3a). Furthermore, the T-DNA insertion mutant line of atsam 3 from Arabidopsis was identified (Figure 3b-d). 
The T-DNA was inserted in the upstream region of the AtSAMS3 promoter (at $765 \mathrm{bp}$ ) (Figure $3 \mathrm{~b}, \mathrm{c}$ ) and the expression level of AtSAMS3 was significantly decreased in the atsam3 mutant (Figure 3d,e). In addition, the construct overexpressing BvM14-SAMS2 was also transformed into the atsam3 mutant background and two homozygous $\mathrm{T}_{3}$ complementation lines (CO1 and $\left.\mathrm{CO} 2\right)$ were selected. Furthermore, the content of SAM was also detected in different Arabidopsis seedlings (Figure 3e). The BvM14-SAMS2-overexpressed transgenic lines showed higher levels of SAM than the wild type (WT), and AtSAMS3 konckdown mutant (KO) line exhibited much lower SAM levels than WT.

(a)

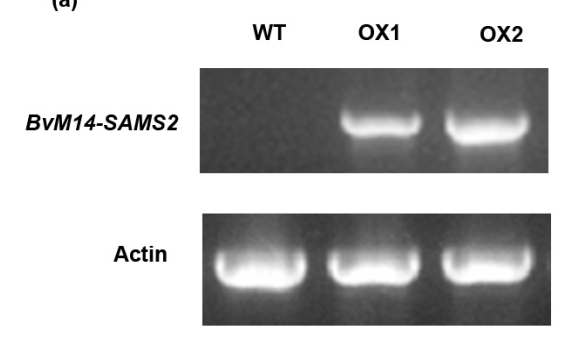

(d)

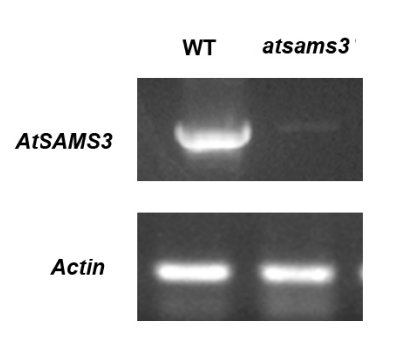

(b)

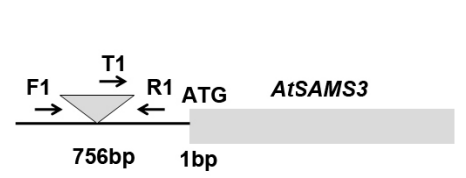

(c)

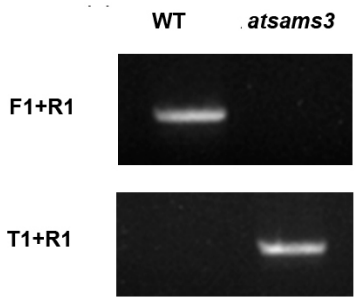

(e)

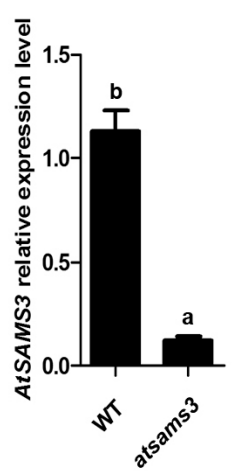

(f)

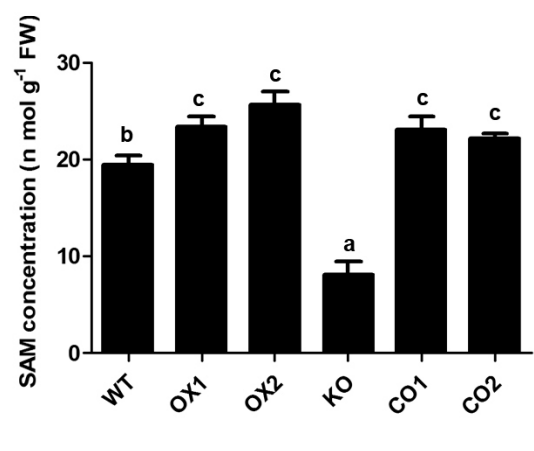

Figure 3. Identification of atsams3 mutant and overexpressed BvM14-SAMS2 in Arabidopsis plants. (a) quantitative reverse transcription-polymerase chain reaction (RT-PCR) analysis of the expression levels of overexpressed BvM14-SAMS2 (OX1 and OX2) in Arabidopsis plants; (b) Structure of the AtSAMS3 gene. The T-DNA insertional site was $756 \mathrm{bp}$ upstream of the start codon, as indicated by a triangle. The primers used to identify the T-DNA insertion were marked with arrows; (c) PCR analysis of the T-DNA insertion in the atsams3 mutant (KO); (d) RT-PCR analysis of the expression levels of AtSAMS3 in atsams3 mutant and wild type (WT); (e) Real-time PCR analysis of the expression levels of AtSAMS3 in the atsams3 mutant; (f) The concentration of $S$-adenosylmethionine (SAM) in 20-day old whole seedlings of wild type (WT), overexpressed BvM14-SAMS2 (OX1 and OX2), AtSAMS3 konckdown mutant (KO) and BvM14-SAMS2 in mutant complementation seedlings (CO). Data are the means of three biological replicates (SD) and each replicate contains five seedlings. Different letters indicate significant difference at $p<0.05$.

The transgenic Arabidopsis lines were analyzed in salt stress tolerance on Murashige and Skoog (MS) plates. Overexpression of BvM14-SAMS2 in Arabidopsis did not show growth inhibition under normal conditions. However, obvious wilting was found in all the seedlings under salt stress, the OX lines exhibited lower reduction in fresh weight and root length compared with the wild type or the atsams 3 mutant under salt stress (Figure 4). Similar phenotype was also identified under $\mathrm{H}_{2} \mathrm{O}_{2}$ stress (Figure 4). Furthermore, $\mathrm{KO}$ lines are more sensitive to salt and $\mathrm{H}_{2} \mathrm{O}_{2}$ stresses than the atsams 3 complementation seedlings (CO1/CO2) or wild type. In order to confirm the above results, the transgenic seedlings were treated with salt and $\mathrm{H}_{2} \mathrm{O}_{2}$ stress in soil. After 7 days of the $100 \mathrm{mM}$ salt or $20 \mathrm{mM} \mathrm{H}_{2} \mathrm{O}_{2}$ stress treatments, plants overexpressing BvM14-SAMS2 showed lower levels of wilting than wild type (Figure 5a). In addition, salt and $\mathrm{H}_{2} \mathrm{O}_{2}$ stresses caused a decrease of total chlorophyll content in the control seedlings. Under salt stress conditions, no significant differences 
were found between wild type and BvM14-SAMS2-overexpressed lines. However, the contents of chlorophyll were higher in the overexpressed BvM14-SAMS2 lines than wild type under $\mathrm{H}_{2} \mathrm{O}_{2}$ stress (Figure 5b). In addition, atsams 3 mutants showed higher reduction in chlorophyll contents than WT and $\mathrm{CO}$ lines under salt stress and $\mathrm{H}_{2} \mathrm{O}_{2}$ stress.

(a)
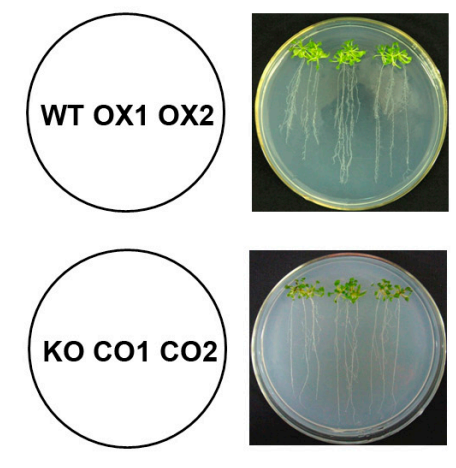

Control
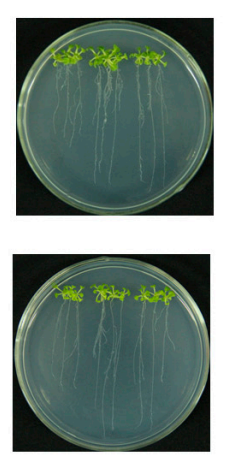

$100 \mathrm{mM} \mathrm{NaCl}$
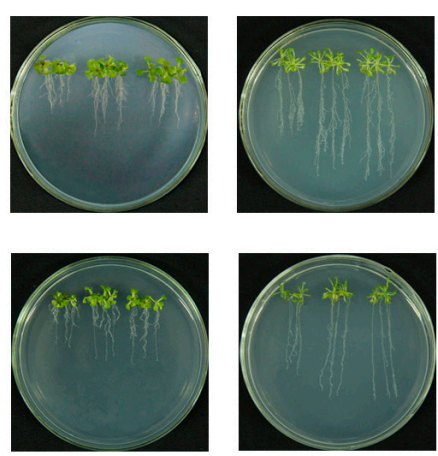

$200 \mathrm{mM} \mathrm{NaCl}$

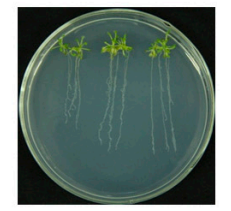

$10 \mathrm{mM} \mathrm{H}_{2} \mathrm{O}_{2}$
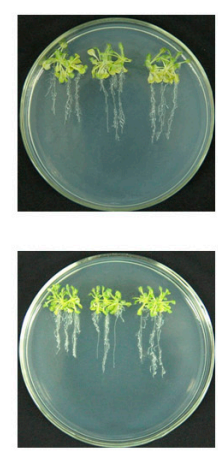

$20 \mathrm{mM} \mathrm{H}_{2} \mathrm{O}_{2}$

(b)

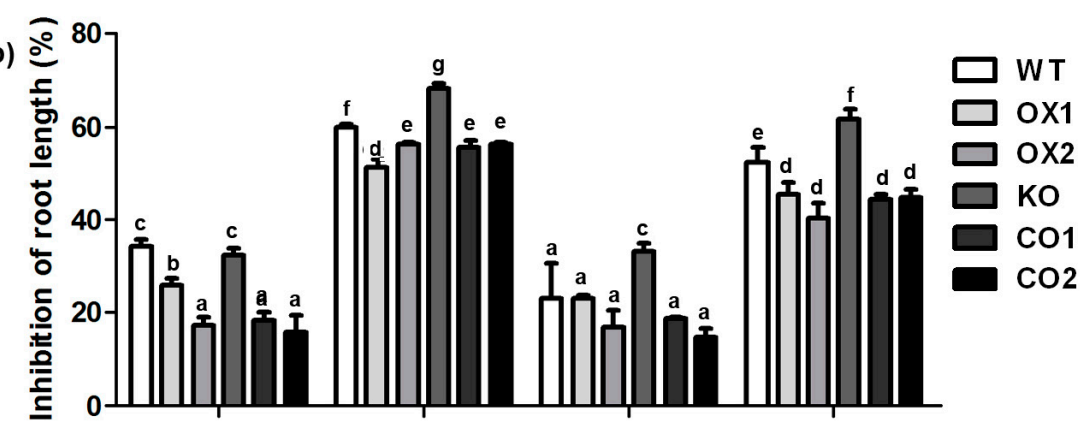

(c)
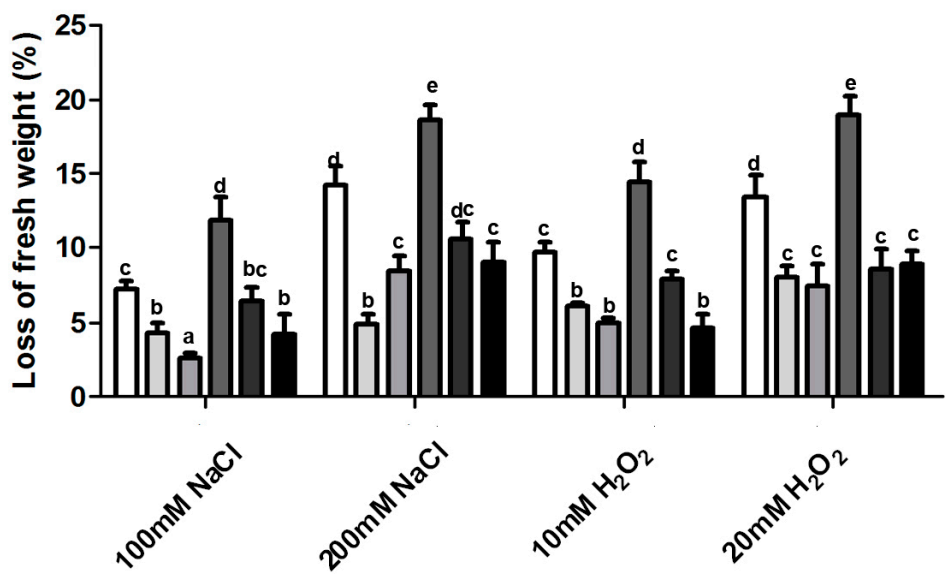

Figure 4. Analysis of salt and $\mathrm{H}_{2} \mathrm{O}_{2}$ tolerance in transgenic Arabidopsis plants in comparison with the wild type and atsams3 mutant. (a) Phenotypes of wild type (WT), BvM14-SAMS2 BvM14-SAMS2-overexpressed seedlings in wild type Arabidopsis (OX), atsams3 mutant (KO), and BvM14-SAMS2 in mutant complementation seedlings (CO) under control and stress conditions. Photographs were taken 14 days after treatment. Inhibition of root length (b); and loss of fresh weight (c) were determined. Data are the means of three biological replicates (SD) and each replicate contains five seedlings. Different letters indicate significant difference at $p<0.05$. 


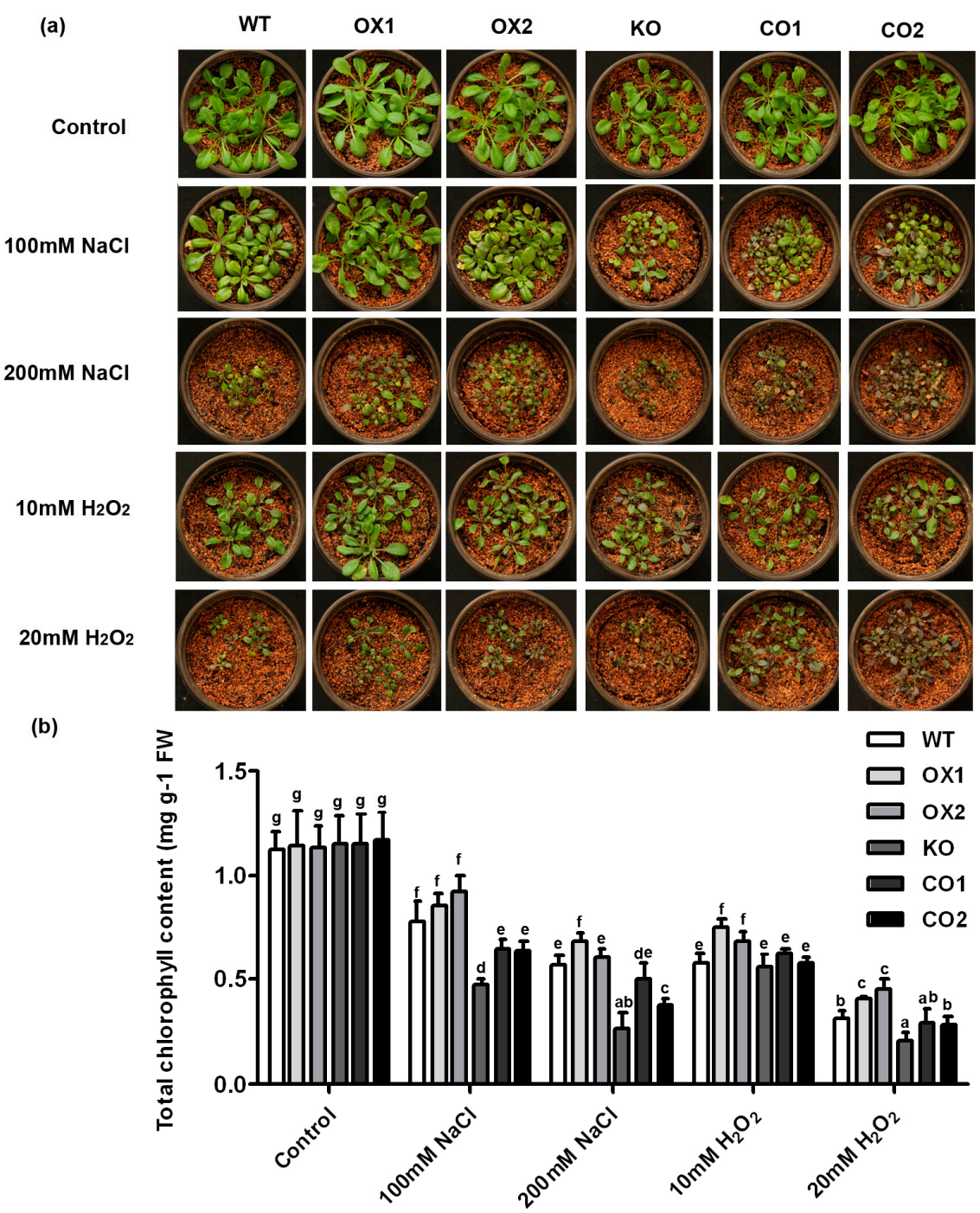

Figure 5. Analysis of salt and $\mathrm{H}_{2} \mathrm{O}_{2}$ tolerance in transgenic Arabidopsis plants in comparison with the wild type and atsams3 mutant in soil. (a) Phenotypes of wild type (WT), BvM14-SAMS2 BvM14-SAMS2-overexpressed seedlings in wild type Arabidopsis (OX), atsams3 mutant (KO), and BvM14-SAMS2 in mutant complementation seedlings (CO) under conditions of control and stress in soil. Photographs were taken 7 days after treatment; Total chlorophyll levels (b) were determined. Data are the means of three biological replicates (SD) and each replicate contains five seedlings. Different letters indicate significant difference at $p<0.05$.

\subsection{Overexpression of BvM14-SAMS2 Increased Antioxidative Activities in Arabidopsis}

Salt stress usually causes oxidation induced lipid membrane damage. The damage can be determined by lipid peroxidation, and the malondialdehyde (MDA) content reflects the level of lipid peroxidation. Under stress conditions, all genotype seedlings exhibited the increasing trend of $\mathrm{H}_{2} \mathrm{O}_{2}$ and MDA contents. However, $\mathrm{KO}$ lines accumulated higher contents of $\mathrm{H}_{2} \mathrm{O}_{2}$ and MDA than WT plants or $\mathrm{CO}$ lines (Figure 6a,b). Furthermore, overexpressed plants showed lower $\mathrm{H}_{2} \mathrm{O}_{2}$ and MDA contents than wild type plants under stress conditions (Figure 6a,b). These results demonstrated that oxidative damage was reduced in the overexpressed plants. In addition, we analyzed the activities of antioxidant enzymes to determine whether the antioxidant enzyme system was involved in reducing the oxidative damage. The activities of antioxidant enzymes including superoxide dismutase (SOD), catalase (CAT) and peroxidase (POD) exhibited higher activities in the OX lines than in WT under salt and $\mathrm{H}_{2} \mathrm{O}_{2}$ stresses (Figure $6 \mathrm{c}-\mathrm{e}$ ). Although stress conditions can induce the activities of these 
antioxidant enzymes in all the plants, the $\mathrm{KO}$ lines exhibited smaller extent of increasing activities than WT under salt and $\mathrm{H}_{2} \mathrm{O}_{2}$ stresses (Figure 6c-e). In addition, no differences in the activity of SOD were detected under the normal conditions between all the seedlings, except that the activities of CAT and POD in the overexpressed plants were higher than WT or KO line under the control conditions.
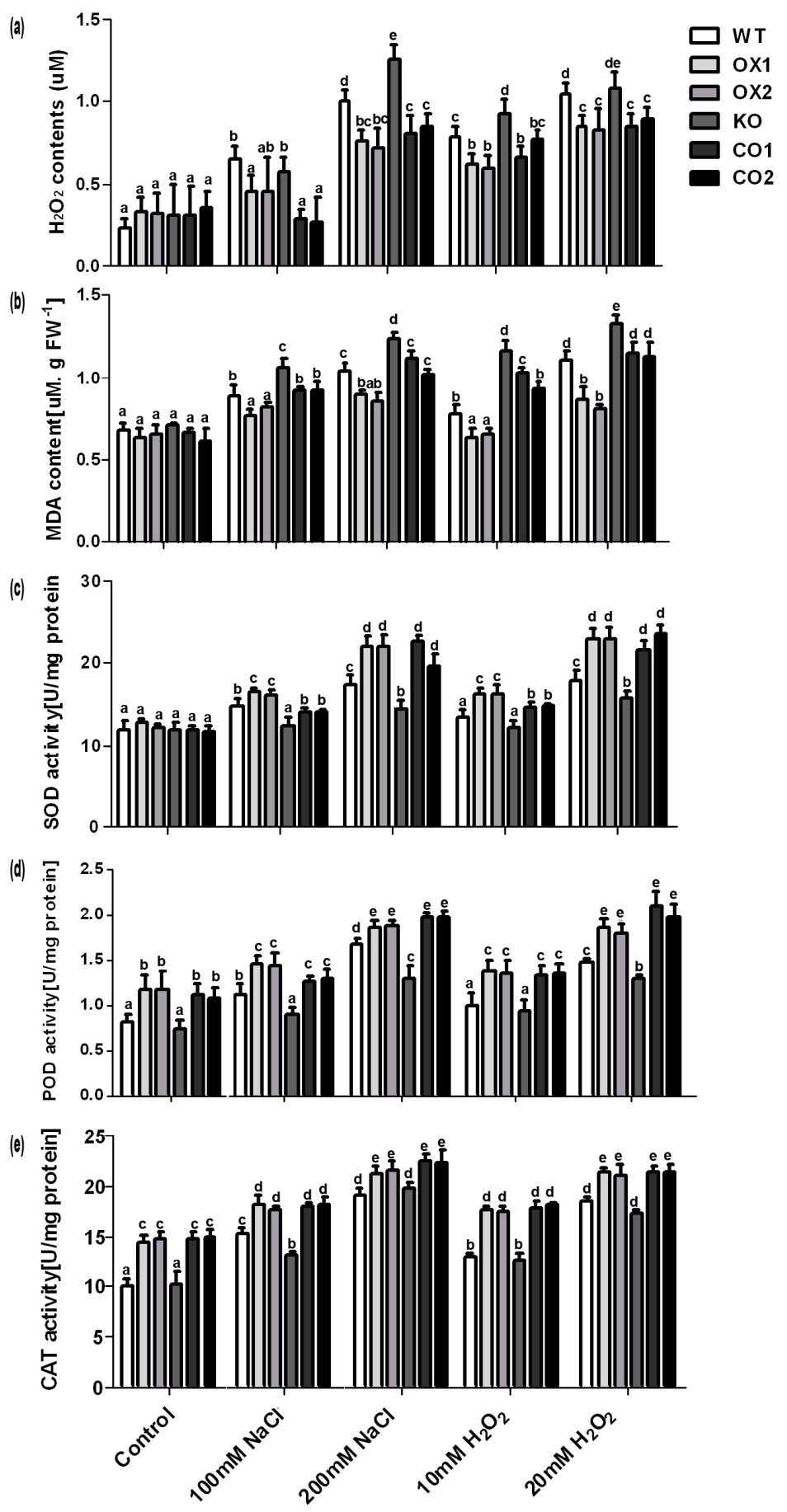

Figure 6. Effects of salt and $\mathrm{H}_{2} \mathrm{O}_{2}$ stresses on antioxidant system activity $\mathrm{H}_{2} \mathrm{O}_{2}$ content (a); malondialdehyde (MDA) content (b); and antioxidant enzyme activities (c-e) were measured in wild type (WT), transgenic BvM14-SAMS2 wild type (WT), BvM14-SAMS2-overexpressed in wild type Arabidopsis (OX), atsams3 mutant (KO) and transgenic BvM14-SAMS2 in the mutant seedlings (CO) leaves. Data are the means of three biological replicates (SD) and each replicate contains five seedlings. Different letters indicate significant difference at $p<0.05$. 


\subsection{Overexpression of BvM14-SAMS2 Greatly Influenced Polyamine Metabolism}

Three types of polyamines, total putrescine (Put), spermidine (Spd) and spermine (Spm) were detected in the overexpressed transgenic plants and wild type. The OX lines showed lower Put concentration than the wild type under control, salt stress and $\mathrm{H}_{2} \mathrm{O}_{2}$ stress conditions (Figure 7a). However, under control and stress conditions, Spd and Spm increased in the OX lines (Figure 7b,c). These results showed that overexpressed BvM14-SAMS2 greatly influenced polyamine metabolism. In addition, proline contents were analyzed (Figure S4) and the results showed that there were no differences between OX lines and wild type under the control condition. Under stress conditions, proline contents increased in both transgenic plants and wild type. However, proline contents were significantly higher in OX lines than in the wild type during salt and $\mathrm{H}_{2} \mathrm{O}_{2}$ stresses, indicating that the wild type plants experienced higher extent of cell damage than the transgenic plants under stress conditions.

(a)

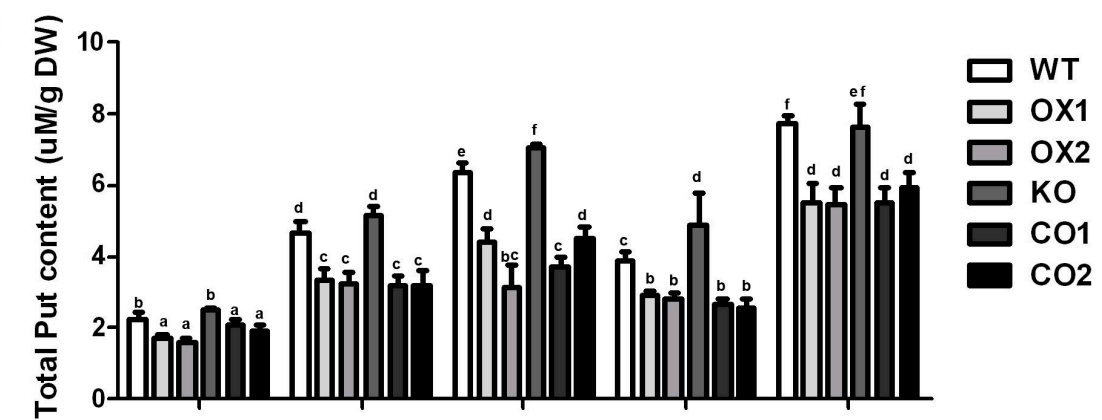

(b)

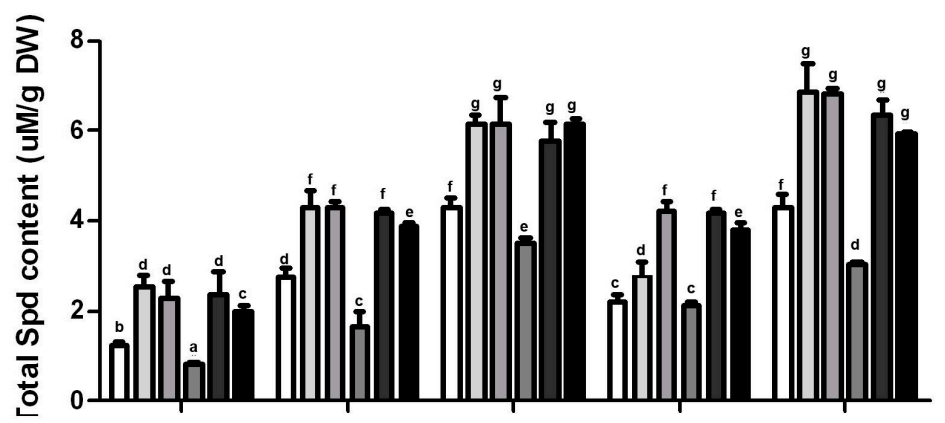

(c)

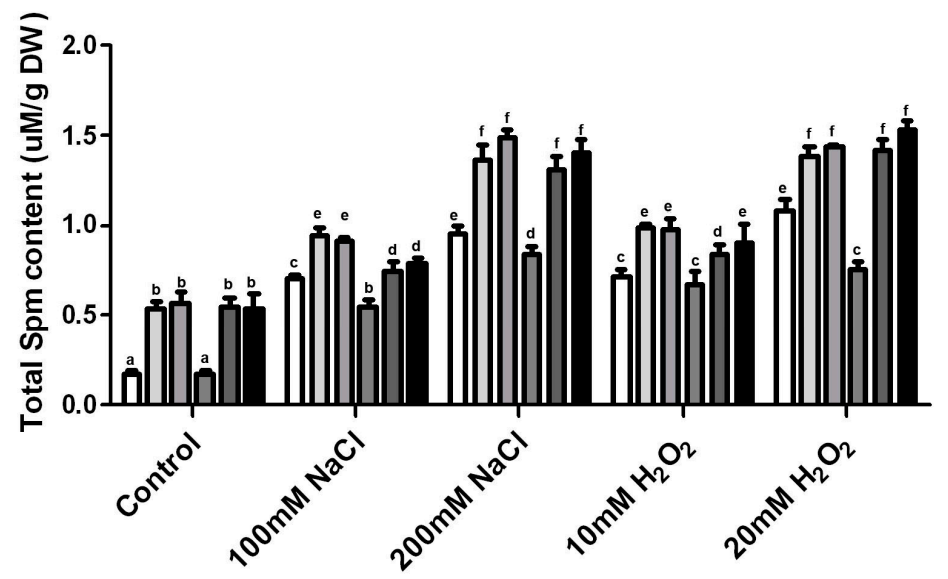

Figure 7. Effects of salt and $\mathrm{H}_{2} \mathrm{O}_{2}$ stresses on polyamines (PAs). Total putrescine (Put) content (a); total spermidine (Spd) content (b); total spermine (Spm) content (c) in wild type (WT), transgenic BvM14-SAMS2 seedlings in wild type Arabidopsis (OX), atsams3 mutant (KO) and BvM14-SAMS2 in mutant complementation seedlings (CO) leaves. Data are the means of three biological replicates with standard deviation (SD), and each replicate contains five seedlings. Different letters indicate significant difference at $p<0.05$. 


\section{Discussion}

The BvM14-SAMS2 characterized in this study was salt-stress induced in roots and leaves of the sugar beet M14 line. Our results are consistent with previous findings of the induction of SAMS expression by salt, cold, drought and $\mathrm{H}_{2} \mathrm{O}_{2}$ [28-30]. Furthermore, overexpression of BvM14-SAMS2 in Arabidopsis led to significant increases in salt and $\mathrm{H}_{2} \mathrm{O}_{2}$ stress tolerance (Figure 4). Photosynthesis, as the most important and complex physiological process of plants, is severely affected by many abiotic stresses. It is reported that salt stress reduced the level of photosynthetic pigments. Usually, the level of photosynthetic pigment is thought to be a biochemical indicator for evaluating salinity tolerance in plants. The KO lines showed a decrease in the total chlorophyll content compared to WT under the stress conditions (Figure 5). Therefore, the decreased chlorophyll content clearly indicates the sensitivity of the $\mathrm{KO}$ line to salt and $\mathrm{H}_{2} \mathrm{O}_{2}$ stresses.

SAMS in Arabidopsis is encoded by four genes. AtSAMS1 and AtSAMS2 are expressed in most of plant tissues, including leaves, roots and flowers [31], whereas AtSAMS4 is expressed predominantly in pollen [32]. Our data indicate that AtSAM3 is also widely expressed in different plant tissues, and showed relatively high expression levels in roots. These results showed that $S A M S$ is involved in many aspects of plant metabolism and development. AtSAMS1 and AtSAMS2 are most similar in sequence and expression patterns, and the double mutant atsams1/atsams 2 showed decreases in ethylene [31]. Furthermore, the atsam 4 mutant was impaired in pollen tube growth and reduced seed production [32]. Moreover, over-expression of the AtSAMS1 in Arabidopsis leads to a dwarf phenotype [31]. In this study, overexpression of BvM14-SAMS2 did not cause the dwarf phenotype. This result is similar to the overexpression of a potato SAMS in Arabidopsis, and the transgenic Arabidopsis lines exhibited high salt and drought stress tolerance [33]. Clearly, the SAMS gene family had function diversity and species specificity. In addition, atsams3 plants decreased SAM content by more than $50 \%$, as compared to the WT plants (Figure 3f). We speculate that different SAMSs catalyze SAM production at different seedling developmental stages, and AtSAMS3 may play a predominantly role in the 20-day old seedlings.

Reactive oxygen species (ROS) and MDA contents are proposed to be indicators of oxidative stress. Usually, reducing the use of absorption light energy caused by inhibition of calvin cycle enzyme under stress conditions will promote production of ROS [34]. Plants possess efficient enzymatic antioxidant defense systems to protect the cells from oxidative damage by scavenging ROS. For example, SOD dismutates superoxide radicals to $\mathrm{H}_{2} \mathrm{O}_{2}$, which is sequentially scavenged by CAT and POD [35]. Other reports showed that exogenous Spd enhanced chilling tolerance in tomato through enhancing the expression of SOD, POD, CAT and ascorbate peroxidase (APX), and their activities in tomato leaves [36]. Meanwhile, nitric oxide (NO) induced by Spd plays a crucial role in regulating these antioxidant enzymes. Similarly, in our study, the activities of CAT and POD were higher in the BvM14-SAMS2 overexpression plants than WT or atsams 3 mutant under control and stress conditions. In addition, the low accumulation of $\mathrm{H}_{2} \mathrm{O}_{2}$ and MDA after $\mathrm{H}_{2} \mathrm{O}_{2}$ or salt stress in the BvM14-SAMS2-overexpressed plants was observed (Figure 6). These results showed that the OX lines possessed high antioxidant enzyme activities that help them to better cope with the stress conditions than the other plants. Furthermore, although the activity of SOD was not different between the genotypes in control conditions, the BvM14-SAMS2-overexpressed transgenic lines showed higher activity than WT or mutant under stress conditions. These results were similar to a previous study [37], where SOD was activated to reduce the ROS levels in TaWRKY44 overexpression transgenic lines after drought and salt stresses [37]. Usually, SOD provides the first line of defense against ROS by catalyzing the dismutation of $\mathrm{O}_{2}{ }^{-}$to oxygen and $\mathrm{H}_{2} \mathrm{O}_{2}$. Thus, our result indicated the antioxidant enzymes involved in first line of defense in BvM14-SAMS2 overexpression plants function more effectively than the WT or KO line.

Recently, several studies have shown the interplay between PAs and signal molecules (e.g., abscisic acid (ABA) and ethylene) under abiotic stresses [38]. It is reported that exogenous Put significantly increased the ABA content in tomato [38]. Furthermore, the expression levels of genes related to ethylene biosynthesis and ABA response were up-regulated in SbSAMS-overexpressing Arabidopsis lines, and the transgenic Arabidopsis plants exhibited higher salt and drought stress tolerance than 
control plants [33]. Taken together, it is speculated that, under salt or $\mathrm{H}_{2} \mathrm{O}_{2}$ stresses, the increased Spd and Spm contents due to the overexpressed BvM14-SAMS2 may affect the stress-related genes including the ethylene and ABA genes responsible for abiotic stress response and tolerance.

In the process of PA synthesis, SAM is converted to decarboxylated $S$-adenosylmethionine (dcSAM), which can supply an aminopropyl group donor for the synthesis of PA. PA is well-known to play an important role in regulating plant adaptation to abiotic stresses [19]. PAs have been reported to scavenge ROS in plants [39] and are thought to be membrane protectors [40]. The contents of the diamine (Put) and triamine (Spd and Spm) were analyzed here. The levels of these common PAs were induced under salt stress conditions in the wild type plants. However, the level of Put was much lower in the BvM14-SAMS2 overexpression lines under both control and salt stress conditions, while the contents of Spd and Spm were much higher in the BvM14-SAMS2 overexpression lines, leading to a high ratio of $(\mathrm{Spd}+\mathrm{Spm}) /$ Put. Other reports showed that Spd and Spm play a vital role in maintaining the thylakoid membrane integrity. Nevertheless, Put may be involved in depolarization of the membrane [21,41]. Therefore, a high ratio of (Spd + Spm)/Put in the BvM14-SAMS2 overexpression lines may be an important factor for the salt stress tolerance in the M14 plants. This trend was observed not only in the sugar beet M14 under control and salt stress conditions, but also in tomato plants under high level alkali stress [21]. It is reported that arginine decarboxylase (ADC) and omithine decarboxylase (ODC), two key enzymes in Put biosynthesis, exhibited much higher activities in SISAMS overexpression lines under alkali stress, while they did not cause higher accumulation of Put. They speculated that up-regulation of SISAMDC and SISPDS may be the main cause of this phenomenon. High levels of Put were quickly converted to Spm and Spd by SISAMDC and SISPDS. Thus, it may be concluded that salt or $\mathrm{H}_{2} \mathrm{O}_{2}$ stress tolerance induced by overexpressing the BvM14-SAMS2 might be involved in increasing the SAM levels for generating Put (Figure 3f), and enhanced conversion of Put to Spd and Spm has been suggested to play important roles in plant tolerance to stress conditions.

\section{Materials and Methods}

\subsection{Plant Materials and Growth Conditions}

Seeds of monosomic addition line M14 were sown in vermiculite and watered daily. After one week, seedlings were transferred to hydroponic containers with Hoagland solution. Seedlings were cultivated in a greenhouse at Heilongjiang University with a $12 \mathrm{~h} / 12 \mathrm{~h} \mathrm{light} /$ dark, a $450 \mu \mathrm{mol} \cdot \mathrm{m}^{-2} \cdot \mathrm{s}^{-1}$ light intensity, a $24{ }^{\circ} \mathrm{C} / 20{ }^{\circ} \mathrm{C}$ day/night temperature, and a relative humidity of $70 \%$. Arabidopsis growth and treatment were conducted as previously described [27].

\subsection{Construction of a Subtractive cDNA Library}

Total RNAs were extracted using TRIzol reagent (Invitrogen, Carlsbad, CA, USA) from the salt stress and the control samples and mRNA was selected by the Oligotex mRNA Kit (Qiagen, Los Angeles, CA, USA). A subtractive cDNA library was generated by the method of our previous report using the salt-treated roots and leaves as the tester and the control roots and leaves as the driver [6].

\subsection{Molecular Cloning of BvM14-SAMS2 Gene and Sequence Analysis}

An EST named as Me-359 matching to BvM14-SAMS2 was identified. The 0.4-kb cDNA sequence was amplified by the method of reverse transcription RT-PCR using two primers: 5'-GTCTGATGATGTGGGTCTTGATGCT-3' (sense primer) and 5'-GAGTCTTACCATCAGGTCTC AGCCA-3' (antisense primer). Furthermore, the full length of BvM14-SAMS2 was acquired by the method of Smart-RACE (Clontech, MountainView, CA, USA). Phylogenetic tree of BvM14-SAMS genes was made using the ClustalX program combined with MEGA 4 software [42]. 


\subsection{Real-Time Quantitative PCR}

First-strand cDNA was generated from $0.5 \mu \mathrm{g}$ of total RNA, using ReverTra Ace reverse transcriptase (Toyobo, Tokyo, Japan). The BvM14-SAMS2 specific primers (5'-GTCTGATGATGTGGGTCTTGATGCT-3' and $5^{\prime}$-GAGTCTTACCATCAGGTCTCAGCCA- $3^{\prime}$ ) were used for real-time quantitative RT-PCR. In order to verify specific of BvM14-SAMS2 primer, we conducted an analysis using Primer-BLAST tool in sugar beet (Beta vulgaris) genome. This pair of primers was specifically matched on SAMS2 in sugar beet genome (Figure S5). Furthermore, randomly-selected 10 positive clones from PCR products from this pair of primers were sequenced, and only BvM14-SAMS2 sequences can be identified. The $18 \mathrm{~S}$ rRNA gene (primers: $5^{\prime}$-CCCCAATGGATCCTCGTTA- $3^{\prime}$ and $5^{\prime}$-TGACGGAGAATTAGGGTTCG-3') was used as an internal control. The reaction system contained aliquots of cDNA $(1 / 20)$ of $1 \mu \mathrm{L}, 150 \mathrm{nM}$ each for forward and reverse primers and $5 \mu \mathrm{L}$ SYBR Premix Ex Taq (Takara, Kusatsu Shiga, Japan) in total for the $10 \mu \mathrm{L}$ PCR mixture. The cycle threshold (CT) for internal control should be between 15 and 20. A negative control without cDNA template was always included. The experiment was conducted by a LightCycler 480 (Roche, Penzberg, Germany) instrument according to the manufacturer's instructions. Triplicate quantitative assays were performed on each cDNA sample.

\subsection{Isolation of T-DNA Insertion Mutants in AtSAMS3}

Arabidopsis T-DNA insertion lines were identified for AtSAMS3 mutation by PCR. Specific primers for the left and right borders of the T-DNA and for AtSAMS3 (F1: 5'-CTAGATCTCATTGTCTGAACACAGTT-3' ' R1: 5'-CGTACAGGAACCATGGCTCCGCTTT-3', T1: 5'-TAGCATCTGAATTTCATAACCAATCTCGATACAC-3') were used to identify mutant lines.

\subsection{Constitutive Expression of BvM14-SAMS2 in Arabidopsis and Stress Tolerance Analysis}

The coding region of the BvM14-SAMS2 gene was amplified using primers (5'-GCG AGATCTTCTCTCACTCTCTTCGTCCAGG-3 ${ }^{\prime}$ and 5'-GCGACTAGTGCATTACGCAGGGATTTTC- $3^{\prime}$ ). Then, it was ligated into the PMD18-T vector. It was cut with BglII and SpeI and ligated into the BglII and SpeI sites of a binary vector pCAMBIA1305.1 under the control of CaMV35S promoter. The construct was introduced into the Agrobacterium tumefaciens EHA105. Arabidopsis was transformed by the floral dip method [27]. The expression of BvM14-SAMS2 in different homozygous lines selected at the concentration of $50 \mu \mathrm{g} / \mathrm{mL}$ Kanamycin was confirmed by the method of RT-PCR. The content of chlorophyll was measured in accordance with a previous report [43].

\subsection{Determination of Antioxidant Enzyme Activities, Lipid Peroxidation, $\mathrm{H}_{2} \mathrm{O}_{2}$ Concentration, $\mathrm{SAM}$ Concentration and Polyamine Metabolism}

Measurement of concentration $\mathrm{H}_{2} \mathrm{O}_{2}$ was performed as previously described [21]. For the antioxidant enzyme assays, SOD activity was measured by analyzing its ability to inhibit the photochemical reduction of nitrobluetetrazolium following the method of Guo et al. [22]. CAT and POD activities were analyzed according to a previous report [21]. SAM concentration was determined following the method of Roeder et al. [44]. PA contents were assayed in accordance with a method described by Hu et al. [20]. Lipid peroxidation was estimated by determining the malondialdehyde (MDA) content in the leaves. For MDA extraction, fresh leaf samples $(0.5 \mathrm{~g})$ were homogenized with $0.1 \%$ trichloroacetic acid (TCA). The homogenate was then centrifuged at $15,000 \times g$ for $10 \mathrm{~min}$. An aliquot $(1 \mathrm{~mL})$ of the supernatant was mixed to $4 \mathrm{~mL}$ of $20 \%$ TCA prepared in $0.5 \%$ thiobarbituric acid (TBA) and incubated at $90{ }^{\circ} \mathrm{C}$ for $30 \mathrm{~min}$ in a shaking water bath. The reaction was stopped in ice bath. The samples were then centrifuged at $10,000 \times g$ for $5 \mathrm{~min}$, and the absorbance of the supernatant was measured at 532 and $600 \mathrm{~nm}$. 


\subsection{Statistical Analysis}

All the data were subjected to analysis of variance according to the model for completely randomized design using an SPSS program (SPSS Inc., Chicago, IL, USA). Differences among means of treatments and plant lines were evaluated by the Duncan's test at 0.05 probability level.

\section{Conclusions}

In summary, the expression of BvM14-SAMS2 is significantly induced by salt treatment. Our study showed that overexpression of BvM14-SAMS2 significantly conferred salt and $\mathrm{H}_{2} \mathrm{O}_{2}$ stress tolerance in transgenic Arabidopsis plants. The functions of BvM14-SAMS2 are mainly accomplished through increased accumulation of Spd, Spm and activities of the antioxidant system, which are involved in scavenging ROS under stress conditions.

Supplementary Materials: Supplementary materials can be found at www.mdpi.com/1422-0067/18/4/847/s1.

Acknowledgments: Research in the HL lab was supported by the National Science Foundation of China (Project 31471552: The response of antioxidant enzymes to salt stress in sugar beet M14, and Project 31401441: Identification of root variation related proteins in sugar beet (Beta vulgaris L.) monosomic addition line M14 using iTRAQ analysis); and also The Common College Science and Technology Innovation Team of Heilongjiang Province (2014TD004). Support was received also from the Natural Science Foundation of Heilongjiang Province (project No. C2016048: A preliminary study on the molecular drought tolerance mechanism of 510 strains of sugar beet), and the Youth Science Foundation of Heilongjiang University (Project QL201511: A preliminary study on salt tolerance mechanism of 510 strains of sugar beet).

Author Contributions: Haiying Li and Sixue Chen compiled and edited the manuscript. Haiying Li is principal investigator of the project and conceived the overall concept of the study. Yuguang Wang, Chunquan Ma, Jingdong Nan and Dan Gu participated in the sampling, carried out the experiments and statistical analysis. All authors read and approved the final manuscript.

Conflicts of Interest: The authors declare no conflict of interest.

\section{References}

1. Zhu, J.K. Genetic analysis of plant salt tolerance using Arabidopsis. Plant Physiol. 2000, 124, 941-948. [CrossRef] [PubMed]

2. Zhu, J.K. Plant salt tolerance. Trends Plant Sci. 2001, 6, 66-71. [CrossRef]

3. Munns, R.; Tester, M. Mechanisms of salinity tolerance. Annu. Rev. Plant Biol. 2008, 59, 651-681. [CrossRef] [PubMed]

4. Turan, M.A.; Elkarim, A.H.A.; Taban, N.; Taban, S. Effect of salt stress on growth, stomatal resistance, proline and chlorophyll concentrations on maize plant. Afr. J. Agric. Res. 2009, 4, 893-897.

5. Barkla, B.J.; Castellanos-Cervantes, T.; de León, J.L.; Matros, A.; Mock, H.P.; Perez-Alfocea, F.; Salekdeh, G.H.; Witzel, K.; Zörb, C. Elucidation of salt stress defense and tolerance mechanisms of crop plants using proteomics-Current achievements and perspectives. Proteomics 2013, 13, 1885-1900. [CrossRef] [PubMed]

6. Yang, L.; Ma, C.; Wang, L.; Chen, S.; Li, H. Salt stress induced proteome and transcriptome changes in sugar beet monosomic addition line M14. J. Plant Physiol. 2012, 169, 839-850. [CrossRef] [PubMed]

7. Yang, L.; Zhang, Y.; Zhu, N.; Koh, J.; Ma, C.; Pan, Y.; Yu, B.; Chen, S.; Li, H. Proteomic analysis of salt tolerance in sugar beet monosomic addition line M14. J. Proteome Res. 2013, 12, 4931-4950. [CrossRef] [PubMed]

8. Zhang, Y.; Lai, J.; Sun, S.; Li, Y.; Liu, Y.; Liang, L.; Chen, M.; Xie, Q. Comparison analysis of transcripts from the halophyte Thellungiella halophila. J. Integr. Plant Biol. 2008, 50, 1327-1335. [CrossRef] [PubMed]

9. Zhang, L.; Ma, X.L.; Zhang, Q.; Ma, C.L.; Wang, P.P.; Sun, Y.F.; Zhao, Y.X.; Zhang, H. Expressed sequence tags from a NaCl-treated Suaeda salsa cDNA library. Gene 2001, 267, 193-200. [CrossRef]

10. Zouari, N.; Saad, R.B.; Legavre, T.; Azaza, J.; Sabau, X.; Jaoua, M.; Masmoudi, K.; Hassairi, A. Identification and sequencing of ESTs from the halophyte grass Aeluropus littoralis. Gene 2007, 404, 61-69. [CrossRef] [PubMed]

11. Jha, B.; Agarwal, P.K.; Reddy, P.S.; Lal, S.; Sopory, S.K.; Reddy, M.K. Identification of salt-induced genes from Salicornia brachiata, an extreme halophyte through expressed sequence tags analysis. Genes Genet. Syst. 2009, 84, 111-120. [CrossRef] [PubMed] 
12. Askari, H.; Edqvist, J.; Hajheidari, M.; Kafi, M.; Salekdeh, G.H. Effects of Salinity levels on proteome of Suaeda aegyptiaca leaves. Proteomics 2006, 6, 2542-2554. [CrossRef] [PubMed]

13. Pang, Q.; Chen, S.; Dai, S.; Chen, Y.; Wang, Y.; Yan, X. Comparative proteomics of salt tolerance in Arabidopsis thaliana and Thellungiella halophila. J. Proteome Res. 2010, 9, 2584-2599. [CrossRef] [PubMed]

14. Wang, J.; Meng, Y.; Li, B.; Ma, X.; Lai, Y.; Si, E.; Yang, K.; Xu, X.; Shang, X.; Wang, H.; Wang, D. Physiological and proteomic analyses of salt stress response in the halophyte Halogeton glomeratus. Plant Cell Environ. 2015, 38, 655-669. [CrossRef] [PubMed]

15. Wang, X.; Fan, P.; Song, H.; Chen, X.; Li, X.; Li, Y. Comparative proteomic analysis of differentially expressed proteins in shoots of Salicornia europaeaunder different salinity. J. Proteome Res. 2009, 8, 3331-3345. [CrossRef] [PubMed]

16. Roje, S. S-Adenosyl-L-methionine: Beyond the universal methyl group donor. Phytochemistry 2006, 67, 1686-1698. [CrossRef] [PubMed]

17. Nagel, J.; Culley, L.K.; Lu, Y.; Liu, E.; Matthews, P.D.; Stevens, J.F.; Page, J.E. EST analysis of hop glandular trichomes identifies an $\mathrm{O}$-methyltransferase that catalyzes the biosynthesis of xanthohumol. Plant Cell 2008, 20, 186-200. [CrossRef] [PubMed]

18. Köllner, T.G.; Lenk, C.; Zhao, N.; Seidl-Adams, I.; Gershenzon, J.; Chen, F.; Degenhardt, J. Herbivore-induced SABATH methyltransferases of maize that methylate anthranilic acid using S-adenosyl-L-methionine. Plant Physiol. 2010, 153, 1795-1807. [CrossRef] [PubMed]

19. Jang, S.J.; Wi, S.J.; Choi, Y.J.; An, G.; Park, K.Y. Increased polyamine biosynthesis enhances stress tolerance by preventing the accumulation of reactiveoxygen species:T-DNA mutational analysis of Oryza sativa lysine decarboxylase-like protein 1. Mol. Cells 2012, 34, 251-262. [CrossRef] [PubMed]

20. Hu, X.; Zhang, Y.; Shi, Y.; Zhang, Z.; Zou, Z.; Zhang, H.; Zhao, J. Effect of exogenous spermidine on polyamine content and metabolism in tomato exposed to salinity-alkalinity mixed stress. Plant Physiol. Biochem. 2012, 57, 200-209. [CrossRef] [PubMed]

21. Gong, B.; Li, X.; VandenLangenberg, K.M.; Wen, D.; Sun, S.; Wei, M.; Li, Y.; Yang, F.; Shi, Q.; Wang, X. Overexpression of $S$-adenosyl-L-methionine synthetase increased tomato tolerance to alkali stress through polyamine metabolism. Plant Biotechnol. J. 2014, 12, 694-708. [CrossRef] [PubMed]

22. Guo, Z.; Tan, J.; Zhuo, C.; Wang, C.; Xiang, B.; Wang, Z. Abscisic acid, $\mathrm{H}_{2} \mathrm{O}_{2}$ and nitricoxide interactions mediated cold-induced $S$-adenosylmethionine synthetase in Medicag osativa subsp. falcata that confers cold tolerance through up-regulating polyamine oxidation. Plant Biotechnol. J. 2014, 12, 601-612. [CrossRef] [PubMed]

23. Qi, Y.C.; Wang, F.F.; Zhang, H.; Liu, W.Q. Overexpression of Suadea salsa S-adenosylmethionine synthetase gene promotes salt tolerance in transgenic tobacco. Acta Physiol. Plant 2010, 32, 263-269. [CrossRef]

24. Li, H.; Cao, H.; Wang, Y.; Pang, Q.; Ma, C.; Chen, S. Proteomic analysis of sugar beet apomictic monosomic addition line M14. J. Proteom. 2009, 73, 297-308. [CrossRef] [PubMed]

25. Ge, Y.; He, G.; Wang, Z.; Guo, D.; Qin, R.; Li, R. GISH and BAC-FISH study of apomicitic Beta M14. Sci. China Ser. C Life Sci. 2007, 37, 209-216.

26. Guo, D.; Kang, C.; Liu, L.; Li, Y. Study of apomixis in theallotriploid beet (VVC). Agric. Sci. China 1999, 32, 1-5.

27. Wang, Y.; Zhan, Y.; Wu, C.; Gong, S.; Zhu, N.; Chen, S.; Li, H. Cloning of a cystatin gene from sugar beet M14 that can enhance plant salt tolerance. Plant Sci. 2012, 191, 93-99. [CrossRef] [PubMed]

28. Li, W.; Han, Y.; Tao, F.; Chong, K. Knockdown of SAMS genes encoding S-adenosyl-L-methionine synthetases causes methylation alterations of DNAs and histones and leads to late flowering in rice. J. Plant Physiol. 2011, 168, 1837-1843. [CrossRef] [PubMed]

29. Lee, J.H.; Chae, H.S.; Lee, J.H.; Hwang, B.; Hahn, K.W.; Kang, B.G.; Kim, W.T. Structure and expression of two cDNAs encoding S-adenosyl-L-methionine synthetase of rice (Oryza sativa L.). Biochim. Biophys. Acta 1997, 1354, 13-18. [CrossRef]

30. Hazarika, P.; Rajam, M.V. Biotic and abiotic stress tolerance in transgenic tomatoes by constitutive expression of S-adenosylmethionine decarboxylase gene. Physiol. Mol. Biol. Plants 2011, 17, 115-128. [CrossRef] [PubMed]

31. Mao, D.; Yu, F.; Li, J.; Van de Poel, B.; Tan, D.; Li, J.; Liu, Y.; Li, X.; Dong, M.; Chen, L.; et al. FERONIA receptor kinase interacts with $S$-adenosylmethionine synthetase and suppresses $S$-adenosylmethionine production and ethylene biosynthesis in Arabidopsis. Plant Cell Environ. 2015, 38, 2566-2574. [CrossRef] [PubMed] 
32. Chen, Y.; Zou, T.; McCormick, S. S-Adenosylmethionine Synthetase 3 is important for pollen tube growth. Plant Physiol. 2016, 172, 244-253. [CrossRef] [PubMed]

33. Kim, S.H.; Kim, S.H.; Palaniyandi, S.A.; Yang, S.H.; Suh, J.W. Expression of potato S-adenosyl-L-methionine synthase (SbSAMS) gene altered developmental characteristics and stress responses in transgenic Arabidopsis plants. Plant Physiol. Biochem. 2015, 87, 84-91. [CrossRef] [PubMed]

34. Zago, E.; Morsa, S.; Dat, J.F.; Alard, P.; Ferrarini, A.; Inzé, D.; Delledonne, M.; van Breusegem, F. Nitric oxide-and hydrogen peroxide-responsive gene regulation during cell death induction in tobacco. Plant Physiol. 2006, 141, 404-411. [CrossRef] [PubMed]

35. Asada, K. The water-water cyclein in chloroplasts: Scavenging of active oxygens and dissipation of excess photons. Annu. Rev. Plant Physiol. Plant. Mol. Biol. 1999, 50, 601-639. [CrossRef] [PubMed]

36. Diao, Q.N.; Song, Y.J.; Shi, D.M.; Qi, H.Y. Nitric oxide induced by polyamines involves antioxidant systems against chilling stress intomato (Lycopersicon esculentum Mill.) seedling. J. Zhejiang Univ Sci. B 2016, 17, 916-930. [CrossRef] [PubMed]

37. Wang, X.; Zeng, J.; Li, Y.; Rong, X.; Sun, J.; Sun, T.; Li, M.; Wang, L.; Feng, Y.; Chai, R.; et al. Expression of TaWRKY44, a wheat WRKY gene, in transgenic tobacco confers multiple abiotic stress tolerances. Front. Plant Sci. 2015, 6, 615. [CrossRef] [PubMed]

38. Diao, Q.; Song, Y.; Shi, D.; Qi, H. Interaction of polyamines, abscisic acid, nitric oxide, and hydrogen peroxide under chilling stress in tomato (Lycopersicon esculentum Mill.) seedlings. Front. Plant Sci. 2017, 8, 203. [CrossRef] [PubMed]

39. Ha, H.C.; Sirisoma, N.S.; Kuppusamy, P.; Zweier, J.L.; Woster, P.M.; Casero, R.A., Jr. The natural polyamine spermine functions directly as a free radical scavenger. Proc. Natl. Acad. Sci. USA 1998, 95, 11140-11145. [CrossRef] [PubMed]

40. Kusano, T.; Berberich, T.; Tateda, C.; Takahashi, Y. Polyamines: Essential factors for growth and survival. Planta 2008, 228, 367-381. [CrossRef] [PubMed]

41. Botella, M.A.; Xu, Y.; Prabha, T.N.; Zhao, Y.; Narasimhan, M.L.; Wilson, K.A.; Nielsen, S.S.; Bressan, R.A.; Hasegawa, P.M. Differential expression of soybean cysteine proteinase inhibitor genes during development and in response to wounding and methyl jasmonate. Plant Physiol. 1996, 112, 1201-1210. [CrossRef] [PubMed]

42. Thompson, J.D.; Gibson, T.J.; Plewniak, F.; Jeanmougin, F.; Higgins, D.G. The CLUSTAL_X windows interface: Flexible strategies for multiple sequence alignment aided by quality analysis tools. Nucleic Acids Res. 1997, 25, 4876-4882. [CrossRef] [PubMed]

43. Lichtenthaler, H.K. Chlorophylls and carotenoids: Pigments of photosynthetic biomembranes. Methods Enzymol. 1987, 148, 350-382.

44. Roeder, S.; Dreschler, K.; Wirtz, M.; Cristescu, S.M.; van Harren, F.J.; Hell, R.; Piechulla, B. SAM levels, gene expression of SAM synthetase, methionine synthase and ACC oxidase, and ethylene emission from N. suaveolens flowers. Plant Mol. Biol. 2009, 70, 535-546. [CrossRef] [PubMed]

(C) 2017 by the authors. Licensee MDPI, Basel, Switzerland. This article is an open access article distributed under the terms and conditions of the Creative Commons Attribution (CC BY) license (http:// creativecommons.org/licenses/by/4.0/). 